\title{
Continuous infusion of recombinant activated factor VII: a review of data in congenital hemophilia with inhibitors and congenital factor VII deficiency
}

This article was published in the following Dove Press journal: Journal of Blood Medicine

\author{
Madhvi Rajpurkar' \\ David L Cooper ${ }^{2}$ \\ 'Division of Hematology/Oncology, \\ Carman and Ann Adams Department \\ of Pediatrics, Wayne State University \\ School of Medicine, Children's \\ Hospital of Michigan, Detroit, MI, \\ USA; ${ }^{2}$ Clinical, Medical and Regulatory \\ Affairs, Novo Nordisk Inc., Plainsboro, \\ $\mathrm{NJ}$, USA
}

Introduction: Continuous infusion (CI) of clotting factors as a replacement therapy for perioperative hemostatic protection has been performed for many years, including with factors VIII and IX and recombinant activated factor VII (rFVIIa). This approach provides steady factor levels without requiring frequent administration of bolus doses.

Aim: To review safety, efficacy, and dosing data regarding CI of rFVIIa for hemostatic management of patients with congenital hemophilia with inhibitors (CHwI) or congenital factor VII deficiency (C7D).

Materials and methods: A literature review identified instances of CI of rFVIIa in patients with $\mathrm{CHwI}$ or C7D undergoing surgery or experiencing bleeding episodes. Data regarding safety, efficacy, and dosing were extracted.

Results: The safety and efficacy of $50 \mathrm{mcg} / \mathrm{kg} / \mathrm{h}$ CI of rFVIIa following a $90 \mathrm{mcg} / \mathrm{kg}$ bolus injection, vs a standard bolus injection regimen, was reported for 24 patients with CHwI undergoing elective surgery in an open-label, randomized, Phase III trial. Efficacy was similar between CI and bolus injection groups at all postoperative time points assessed. Additionally, a postmarketing surveillance study reported effective ( $80 \%)$ and partially effective $(20 \%) \mathrm{CI}$ of rFVIIa in a Japanese cohort of ten patients with CHwI who underwent 15 surgical procedures. Finally, the safety and dosing of rFVIIa CI in 193 and 26 patients with CHwI and C7D, respectively, were reported in 11 prospective studies, 10 retrospective studies, and 30 case reports. No unexpected safety findings were reported.

Conclusion: rFVIIa CI has been performed safely and effectively in patients with CHwI and C7D undergoing surgery and during bleeding episodes in patients with CHwI.

Keywords: rFVIIa, continuous infusion, surgery, bleeding

\section{Introduction}

Continuous infusion (CI) of replacement clotting factor VIII (FVIII) and factor IX (FIX) has been performed for many years in the context of perioperative management of bleeding, and provides a means of ensuring continuous factor activity at a steady level without requiring frequent nursing administration of small bolus doses. ${ }^{1,2}$ After this approach was initially suggested by Brinkhous in the early $1950 \mathrm{~s},{ }^{3}$ experience with CI accumulated in situations requiring intensive FVIII replacement. ${ }^{4-8}$ More recently, interest in this administration approach has been supported by improvements in the stability of newer factor concentrates and the ability to achieve stable hemostatic effect with substantial factor savings (estimated as $20 \%-50 \%){ }^{9}$
Correspondence: Madhvi Rajpurkar Division of Hematology/Oncology, Carman and Ann Adams Department of Pediatrics, Wayne State University School of Medicine, Children's Hospital of Michigan, 390I Beaubien Blvd., Detroit, MI 4820I, USA

Tel +I $31374555 \mid 5$

Fax +I 3137455237

Email mrajpurk@med.wayne.edu 
Advantages of CI are reflected in the current World Federation of Hemophilia guidelines, which include the use of purified FIX as well as FVIII concentrates and state that "continuous infusion avoids peaks and troughs and is considered by some to be advantageous and more convenient." 10 Furthermore, these guidelines state that the use of CI may reduce the amount of clotting factor concentrates administered, and therefore may be cost-effective, particularly in patients with severe hemophilia. Evidence supporting the World Federation of Hemophilia guidelines for CI of FVIII and FIX comes from several studies demonstrating that CI provided similar efficacy to bolus injections (BIs) with higher nadir factor levels and lower drops in hemoglobin and blood transfusion requirements, and reduced overall factor use. ${ }^{11-13}$

Recombinant activated coagulation factor VII (rFVIIa; NovoSeven ${ }^{\circledR}$ RT; Novo Nordisk A/S, Bagsværd, Denmark) is a highly purified recombinant protein, ${ }^{14}$ the development of which began clinically with compassionate/emergency use programs initiated in 1998 and continued through multiple formal clinical studies that were conducted in the subsequent 15-20 years in both the treatment of bleeding and perioperative management settings. ${ }^{15}$ The product is approved by the US Food and Drug Administration for the treatment of bleeding episodes and the prevention of bleeding in surgical interventions or invasive procedures in patients with hemophilia A or B with inhibitors, congenital FVII deficiency (C7D), and Glanzmann's thrombasthenia (GT) with refractoriness to platelets with or without antibodies. It is also indicated for the treatment of bleeding episodes and the prevention of bleeding in surgical interventions or invasive procedures in adults with acquired hemophilia (AH). ${ }^{16}$

Although currently indicated in the US for BI only, several early studies document the use of rFVIIa administered by CI. ${ }^{17}$ Following an initial dose-finding study that randomized patients to two rFVIIa doses for perioperative management, ${ }^{18}$ interest was generated in specifically comparing rFVIIa BI and CI approaches to surgery based on early published experiences with rFVIIa. ${ }^{17,19-22}$ One study specifically reported reduced rFVIIa utilization of CI compared with $\mathrm{BI}$ and a reduction in nursing care required for severe bleeding and perioperative management. ${ }^{17}$ This led to the first randomized trial comparing BI with CI of bypassing agents for perioperative management. ${ }^{23}$ In parallel with the clinical studies, registries continue to capture CI data, and multiple case reports and series have documented successful CI of rFVIIa for perioperative management of patients with congenital hemophilia with inhibitors (CHwI) or C7D. This literature review presents the clinical experience of patients with $\mathrm{CHwI}$ and C7D who were treated with rFVIIa CI. Together, the studies reviewed evaluate the safety and efficacy of rFVIIa $\mathrm{CI}$ in these patient populations.

\section{Materials and methods}

A systematic literature review was conducted to identify patients treated with rFVIIa CI between January 1, 1995 and September 30, 2016 using ProQuest and InsightMeme. Included articles were published in English and were required to present some data from patients with $\mathrm{CHwI}$ or $\mathrm{C} 7 \mathrm{D}$, even if other indicated uses of rFVIIa (ie, AH or GT) were also presented. Articles reporting data exclusive to other indications were excluded. This analysis presents all information available from all publications identified, without attempting to remove any potential duplicate reporting; however, in cases of newer publications that clearly referred to being inclusive of previously reported results, only the updated results were used.

The following search terms were used: $(\mathrm{h} *$ emophilia AND inhibitor*) AND (continuous NEAR/3 (infuse OR infusing OR infusion)) AND (novoseven OR rfviia OR "recombinant factor viia" OR "recombinant coagulation factor vii" OR "recombinant activated factor vii" OR "eptacog alfa") and "factor VII deficien*" AND (continuous NEAR/3 (infuse OR infusing OR infusion)) AND (novoseven OR rfviia OR "recombinant factor viia" OR "recombinant coagulation factor vii" OR "recombinant activated factor vii" OR "eptacog alfa"). Safety, efficacy, and dosing data were extracted from the reports identified, where available.

\section{Results}

The literature search captured a total of 241 patients who experienced 453 bleeding episodes, 223 surgical procedures, and 46 unspecified episodes (bleeds/surgeries) in which rFVIIa CI was used as part of the treatment regimen.

In the context of $\mathrm{CHwI}, 45$ published references were identified. Of these, one reference described a randomized parallel trial (BI vs CI) and one a postmarketing surveillance study. In addition, 9 prospective studies, 9 retrospective studies, 7 case series reporting on two or more patients, and 18 case reports on a single patient were identified. Together, these references included 215 patients treated for 453 bleeding episodes, 177 surgeries or procedures, and 46 unspecified episodes (bleeds/surgeries). Of note, information specific to eleven patients with $\mathrm{AH}$ and two patients with GT could not easily be removed, and therefore, it is included in the overall population consisting primarily of patients with $\mathrm{CHwI}$. 
In the context of C7D, eight published references were identified. These references included two prospective studies, one retrospective study, one case series reporting on two or more patients, and four case reports on a single patient. Data were captured for 26 patients with C7D who were administered rFVIIa CI for a total of 46 surgeries.

\section{Direct comparison of $\mathrm{Cl}$ to $\mathrm{Bl}$ of $\mathrm{rFVlla}$ in patients with $\mathrm{CHwl}$ : pivotal open-label study}

Due to interest in comparing the safety and efficacy of CI vs BI of rFVIIa, Novo Nordisk conducted an open-label, randomized, parallel trial comparing $\mathrm{CI}(\mathrm{n}=12)$ and intravenous $\mathrm{BI}(\mathrm{n}=12)$ of rFVIIa in patients with hemophilia $\mathrm{A}$ or $\mathrm{B}$ with inhibitors who were undergoing elective major surgery. ${ }^{16,23}$ The types of surgeries performed included knee $(n=13)$, hip $(\mathrm{n}=3)$, abdomen/lower pelvis $(\mathrm{n}=2)$, groin/inguinal $(\mathrm{n}=2)$, circumcision $(n=1)$, eye $(n=1)$, frontal/temporal region of cranium $(\mathrm{n}=1)$, and oral cavity $(\mathrm{n}=1)$.

Overall dosing regimens for each treatment group are shown in Figure 1. Prior to surgery, a $90 \mathrm{mcg} / \mathrm{kg}$ bolus dose of rFVIIa was administered to patients in each group; the BI group then received $90 \mathrm{mcg} / \mathrm{kg}$ rFVIIa every 2 hours during the procedure and for the first 5 days, then every 4 hours from days $6-10$, and the CI group received $50 \mathrm{mcg} / \mathrm{kg} / \mathrm{h} \mathrm{rFVIIa}$ during the procedure and for the first 5 days, followed by $25 \mathrm{mcg} / \mathrm{kg} / \mathrm{h}$ from days $6-10$. For both rFVIIa-treated groups, two bolus rescue doses $(90 \mathrm{mcg} / \mathrm{kg})$ were permitted during any 24-hour period.

Efficacy assessments at each time point for both treatment groups are summarized in Table 1. The BI and CI treatment groups showed comparable efficacy in achieving and maintaining hemostasis in major surgery from wound closure through day 10. At 24 hours after surgery, treatment was rated as effective in 12 of 12 patients $(100 \%)$ in the bolus treatment group and in 10 of 12 patients $(83.3 \%)$ in the CI treatment group, and at postoperative day 10 was effective in 9 of 12 patients $(75.0 \%)$ in the bolus treatment group and in 10 of 12 patients $(83.3 \%)$ in the CI treatment group. Median days of rFVIIa dosing, median numbers of additional BIs, and mean total doses were similar between the BI and CI groups (Table 2). The mean total doses of rFVIIa administered were $237.5 \mathrm{mg}$ (BI) and $292.2 \mathrm{mg}$ (CI).

Of the 24 total patients, 7 had serious adverse events (SAEs; 4 in the BI group and 3 in the CI group). Four of these SAEs were considered probably or possibly related to rFVIIa treatment (two events of decreased therapeutic response in each treatment arm). No deaths occurred during the study period.

\section{Postmarketing surveillance study in patients with $\mathrm{CHwl}$}

A postmarketing surveillance study was performed to assess the safety and hemostatic efficacy of rFVIIa administered as a BI and/or by $\mathrm{CI} .{ }^{24}$ The study included 37 Japanese patients with congenital hemophilia A or B with inhibitors $(n=32)$ or $\mathrm{AH}(\mathrm{n}=5)$ undergoing a total of 66 surgical procedures. CI administered after an initial BI of rFVIIa was used in 15 major or minor procedures in ten patients with congenital hemophilia A or B with inhibitors.

Postoperative bleeding control was rated effective or slightly effective in all patients with $\mathrm{CHwI}$ who received rFVIIa CI (Table 3). CI dosing of rFVIIa ranged from $8-60 \mathrm{mcg} / \mathrm{kg} / \mathrm{h}$ over a duration of 5-16 days. Local thrombophlebitis was reported in one patient who received concomitant immune tolerance induction with recombinant FVIII.

\section{Additional prospective studies, retrospective studies, and case reports in patients with $\mathrm{CHwl}$}

In addition to the open-label study and the postmarketing surveillance study, the literature review identified 43 relevant publications containing information on 193 patients with

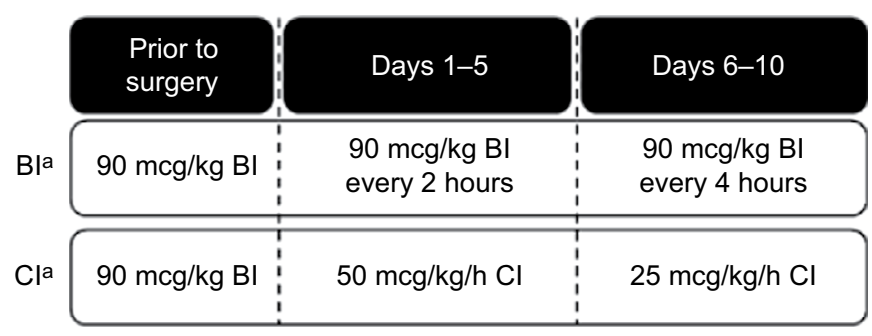

Figure I Open-label study design

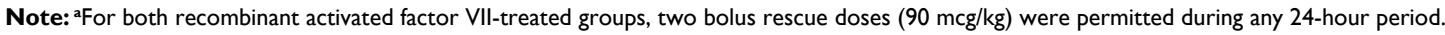
Abbreviations: $\mathrm{Bl}$, bolus injection; $\mathrm{Cl}$, continuous infusion. 
CHwI (including 11 patients with $\mathrm{AH}$ and 2 patients with GT) who experienced 649 bleeding episodes and surgical procedures that were treated with rFVIIa CI. ${ }^{15,19,20,22,25-63}$ These references included 9 reports of prospective series with 84 patients treated for 392 bleeding episodes, 55 surgeries, and 46 bleeds/surgeries; 9 reports of retrospective series with 64 patients treated for 39 bleeding episodes and 64 surgeries; and 25 case reports/series detailing 45 patients treated for 22 bleeding episodes and 31 surgeries.

CI dosing characteristics and adverse events (AEs) possibly or probably related to rFVIIa in patients with CHwI are summarized in Table 4; of note, efficacy was not formally assessed in all these studies. CI dosing in patients with CHwI

Table I Open-label study - efficacy of bolus dosing vs continuous infusion in major surgery in patients with congenital hemophilia with inhibitors

\begin{tabular}{|c|c|c|c|c|}
\hline \multirow[b]{3}{*}{$\begin{array}{l}\text { Postoperative } \\
\text { time point }\end{array}$} & \multicolumn{4}{|l|}{ n (\%) } \\
\hline & \multicolumn{2}{|c|}{$\begin{array}{l}\text { Bolus injection } \\
(90 \mathrm{mcg} / \mathrm{kg}) \\
(\mathrm{n}=12)\end{array}$} & \multicolumn{2}{|c|}{$\begin{array}{l}\text { Continuous infusion } \\
(50 \mathrm{mcg} / \mathrm{kg} / \mathrm{h}) \\
(\mathrm{n}=\mathrm{I} 2)\end{array}$} \\
\hline & Effective & Ineffective & Effective & Ineffective \\
\hline Hour 0 & $12(100.0)$ & $0(0.0)$ & $12(100.0)$ & $0(0.0)$ \\
\hline Hour 8 & $12(100.0)$ & $0(0.0)$ & II (9I.7) & I (8.3) \\
\hline Hour 24 & $12(100.0)$ & $0(0.0)$ & $10(83.3)$ & $2(16.7)$ \\
\hline Hour 48 & $10(83.3)$ & $2(16.7)$ & II (9I.7) & $I(8.3)$ \\
\hline Hour 72 & $9(75.0)$ & $3(25.0)$ & II (9I.7) & I (8.3) \\
\hline Day 4 & II (9I.7) & I (8.3) & $10(83.3)$ & $2(16.7)$ \\
\hline Day 5 & II (9I.7) & I (8.3) & $10(83.3)$ & $2(16.7)$ \\
\hline Day 6 & II (9I.7) & I (8.3) & $10(83.3)$ & $2(16.7)$ \\
\hline Day 7 & $9(75.0)$ & $3(25.0)$ & $10(83.3)$ & $2(16.7)$ \\
\hline Day 8 & $10(83.3)$ & $2(16.7)$ & $10(83.3)$ & $2(16.7)$ \\
\hline Day 9 & $9(75.0)$ & $3(16.7)$ & $10(83.3)$ & $2(16.7)$ \\
\hline Day 10 & $9(75.0)$ & $3(16.7)$ & $10(83.3)$ & $2(16.7)$ \\
\hline
\end{tabular}

Notes: Data from Pruthi et al. ${ }^{23}$ Patients who completed the study early, having achieved hemostasis, were counted as effective at subsequent time points. Patients who discontinued due to treatment failure were counted as ineffective at subsequent time points. Eight patients completed the study early because their bleeding had resolved. Four patients dropped out of the study due to ineffective therapy, and one patient left the study due to a hemarthrosis that was described as an adverse event. One of the patients randomized to the bolus injection arm had an autoimmune inhibitor to coagulation factor VIII and was included in the efficacy analysis. ranged from $2.5-120.0 \mathrm{mcg} / \mathrm{kg} / \mathrm{h}$, and duration of CI dosing ranged from 4 hours to 34 days. Of the 193 patients with CHwI, a total of 38 adverse drug reactions (ADRs) possibly or probably related to administration of rFVIIa were reported in 19 patients, including wound infection or device-related sepsis (6), hemarthrosis (7), and procedural or postprocedural hemorrhage (8).

\section{Prospective studies, retrospective studies, and case reports in patients with C7D}

In the context of C7D, the literature search returned eight relevant publications reporting data from 26 patients who underwent 46 major and minor surgeries and were treated with rFVIIa CI. ${ }^{64-71}$ These references include two prospective studies with 13 patients undergoing 28 surgeries, one retrospective study with 7 patients undergoing 12 surgeries, and 5 case reports/series of 6 patients undergoing 6 surgeries.

$\mathrm{CI}$ dosing characteristics and AEs possibly or probably related to rFVIIa in patients with C7D are summarized in Table 5; of note, efficacy was not formally evaluated in these publications. CI dosing of rFVIIa in patients with C7D who were undergoing surgery ranged from $0.2-30.0 \mathrm{mcg} / \mathrm{kg} / \mathrm{h}$, and duration of $\mathrm{CI}$ dosing ranged from 8 hours to 10 days. Of the 26 patients with C7D, one patient reported a total of two ADRs possibly or probably related to rFVIIa (major perioperative bleeding and development of transient rFVIIa inhibitors).

\section{Discussion}

Perioperative CI of rFVIIa may be a useful alternative to BIs in some circumstances, and use of this administration method has been reported in various patient populations. Potential advantages of CI proposed initially by Schulman et al include the ability to provide patients with constant levels of rFVIIa, possible cost savings associated with the avoidance of peaks in rFVIIa levels based upon demonstrated lower utilization, and reduced administrative burden (hanging

Table 2 Open-label study - dosing by treatment group in patients with congenital hemophilia with inhibitors

\begin{tabular}{|c|c|c|}
\hline Parameter & $\begin{array}{l}\text { Bolus injection } \\
(90 \mathrm{mcg} / \mathrm{kg}) \\
(\mathrm{n}=12)\end{array}$ & $\begin{array}{l}\text { Continuous infusion } \\
(50 \mathrm{mcg} / \mathrm{kg} / \mathrm{h}) \\
(\mathrm{n}=12)\end{array}$ \\
\hline Days of dosing, median (range) & $10(4-15)^{\mathrm{a}}$ & $10(2-116)$ \\
\hline Number of bolus injections, median (range) & $38(36-42)$ & $1.5(0-7)$ \\
\hline Number of additional bolus injections, ${ }^{\mathrm{b}}$ median (range) & $0(0-3)$ & $0(0-4)$ \\
\hline Mean total dose, $\mathrm{mg}$ & 237.5 & 292.2 \\
\hline
\end{tabular}

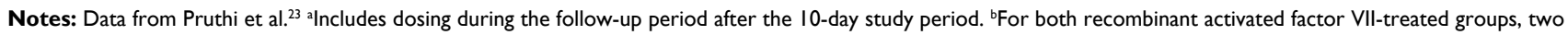
bolus rescue doses $(90 \mathrm{mcg} / \mathrm{kg})$ were permitted during any 24 -hour period. Five patients in the bolus group and four patients in the continuous infusion group required additional bolus doses. 
Table 3 Postmarketing surveillance study - dosing and efficacy of continuous infusion of rFVIla in patients with congenital hemophilia with inhibitors

\begin{tabular}{|c|c|c|c|c|c|c|c|}
\hline \multirow[t]{2}{*}{ Patient } & \multirow{2}{*}{$\begin{array}{l}\text { Age, } \\
\text { years }\end{array}$} & \multirow[t]{2}{*}{ Type of surgery } & \multirow{2}{*}{$\begin{array}{l}\text { Total } \\
\text { dose, } \\
\text { mcg/kg }\end{array}$} & \multicolumn{2}{|l|}{ Dosing regimen } & \multirow[b]{2}{*}{$\begin{array}{l}\text { Treatment } \\
\text { duration, } \\
\text { days }\end{array}$} & \multirow[b]{2}{*}{$\begin{array}{l}\text { Postoperative } \\
\text { control }^{\mathrm{b}}\end{array}$} \\
\hline & & & & $\begin{array}{l}\text { Initial bolus } \\
\text { dose(s), mcg/kg }\end{array}$ & $\begin{array}{l}\text { Continuous } \\
\text { infusion, }^{\mathrm{a}} \\
\mathrm{mcg} / \mathrm{kg} / \mathrm{h}\end{array}$ & & \\
\hline \multicolumn{8}{|c|}{ Hemophilia A } \\
\hline I & I & Port placement & $\mathrm{I}, 830$ & 92 & $14-28$ & 5 & Effective \\
\hline 2 & 32 & Shoulder arthroplasty & 2,520 & $120 \mathrm{q} 3$ hours $\times 8$ & $15-30$ & 6 & Effective \\
\hline \multirow[t]{3}{*}{3} & 11 & Elbow arthroplasty & 5,930 & $60-100$ & $10-30^{c}$ & $38^{d}$ & Effective \\
\hline & 16 & Surgical contracture release & 610 & 202 & 17 & 7 & Effective \\
\hline & 18 & Arthroscopic synovectomy & 5,550 & 98 & $20-60$ & 8 & Effective \\
\hline 4 & 20 & Arthroscopic synovectomy (knee) & 5,470 & $q 2$ hours $\times 12$ & $15-30^{\mathrm{e}}$ & $16^{f}$ & Slightly effective \\
\hline 5 & 7 & Arthroscopic synovectomy (knee) & 1,690 & 100 & $17-26^{\mathrm{e}}$ & $13^{f}$ & Effective \\
\hline \multirow[t]{2}{*}{6} & 19 & $\begin{array}{l}\text { Pneumothorax, chest tube insertion, } \\
\text { debridement }\end{array}$ & 8,870 & $\mathrm{q} 2$ hours $\times 13$ & $10-50$ & 14 & Effective \\
\hline & 19 & $\begin{array}{l}\text { Port placement, thoracoscopic partial } \\
\text { pneumonectomy for pneumothorax }\end{array}$ & 10,320 & $\mathrm{q} 2$ hours $\times 25$ & $10-50$ & 14 & Effective \\
\hline \multicolumn{8}{|c|}{ Hemophilia B } \\
\hline \multirow[t]{2}{*}{7} & 36 & Arthroscopic synovectomy (knee) & 3,680 & 102 q2 hours $\times 9$ & $13-17^{e}$ & $14^{f}$ & Slightly effective \\
\hline & 37 & Arthroscopic synovectomy (knee) & 6,100 & 96 q2 hours $\times 8$ & $8-56^{e}$ & $13^{f}$ & Effective \\
\hline 8 & 12 & Arthroscopic synovectomy (knee) & 3,470 & 102 q2 hours $\times 12$ & $26-34^{\mathrm{e}}$ & $5^{f}$ & Effective \\
\hline \multirow[t]{2}{*}{9} & 15 & Femoral head replacement & 3,890 & 95 q2 hours $\times 12$ & $14-29$ & 7 & Effective \\
\hline & 17 & Femoral head replacement & 5,000 & 100 q2 hours $\times 16$ & $13-33$ & 15 & Slightly effective \\
\hline 10 & 36 & Sclerotherapy for esophageal varices & 580 & NR & 14 & 7 & Effective \\
\hline
\end{tabular}

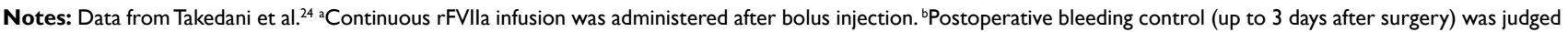
as effective (bleeding stopped or considerably reduced), slightly effective (bleeding slightly reduced), or not effective (bleeding not reduced). ${ }^{\circ}$ Treatment regimen included concomitant immune tolerance induction with recombinant factorVIII from the operative day. ${ }^{\mathrm{d}} \mathrm{rFVIla}$ use before physiotherapy and for regular prophylaxis is included. ${ }^{\mathrm{e}}$ Treatment regimen included preoperative, concomitant, or sequential use of activated prothrombin complex concentrate. 'Other bypassing agents were used in addition to rFVlla. All patients on continuous infusion with $\mathrm{rFV}$ lla received concomitant therapy with tranexamic acid.

Abbreviations: NR, not reported; rFVIla, recombinant activated factor VII.

one infusion bag a day) compared with regular bolus dosing every two or three hours during surgery and until hemostasis or healing has occurred. ${ }^{17,21}$ As noted by Pruthi et al, the planned dosage schedule precluded direct comparison of the required rFVIIa dose of CI vs BI. ${ }^{23}$ Previous investigation demonstrated the biochemical stability and maintenance of sterility of rFVIIa over 24 hours of CI when kept at room temperature, supporting the ability to infuse a constant dose over time..$^{72}$ Our analysis aimed to summarize available safety, efficacy, and dosing data regarding CI of rFVIIa in patients with $\mathrm{CHwI}$ or $\mathrm{C} 7 \mathrm{D}$, and to compare CI outcomes to those of BIs, when available. Overall, we identified a total of 241 patients who experienced 453 bleeding episodes, 223 surgeries, and 46 unspecified episodes (bleeds or surgeries) in which treatment included rFVIIa CI (Table 6). While our analysis of the literature showed that CI of rFVIIa is typically performed undiluted via an infusion pump, it should be noted that there have been other reports that have used conventional pumps and a diluted dose of rFVIIa. For example, one study used $1.7 \mathrm{mg}$ of rFVIIa diluted in $15 \mathrm{~mL}$ of normal saline and infused at $3 \mathrm{~mL} / \mathrm{h} ;{ }^{70}$ another study ${ }^{64}$ used $5.4 \mathrm{mg} \mathrm{rFVIIa}$ from a $5 \mathrm{mg}$ vial and the remaining $0.4 \mathrm{mg}$ from an already opened vial in $50 \mathrm{~mL}$ of sterile water to a final concentration of $108 \mathrm{mcg} / \mathrm{mL}$ and infused at a rate of $15 \mathrm{~mL}$ per 24 hours; and another ${ }^{66}$ reported diluting rFVIIa with sterile water to $2,400 \mathrm{IU} / \mathrm{mL}$ with an infusion rate of $2-3 \mathrm{~mL}$ per 24 hours.

\section{Congenital hemophilia with inhibitors}

In the context of CHwI, identified reports included a pivotal randomized trial, a postmarketing surveillance study, and 43 additional prospective studies, retrospective studies, and case reports/series. In the pivotal trial, CI patients received a $\mathrm{BI}$ of $90 \mathrm{mcg} / \mathrm{kg}$ rFVIIa (consistent with recommended bolus dosing), followed by $50 \mathrm{mcg} / \mathrm{kg} / \mathrm{h} \mathrm{CI}$; in other studies, CI dosing varied, ranging from $8-60 \mathrm{mcg} / \mathrm{kg} / \mathrm{h}$ (postmarketing surveillance study) or $2.5-120 \mathrm{mcg} / \mathrm{kg} / \mathrm{h}$ (additional reports).

Although efficacy was not formally evaluated in the small prospective/retrospective studies and case reports/series, the reported efficacy of rFVIIa CI in the pivotal trial and postmarketing surveillance study ranged from $80-83.3 \%$, and rFVIIa CI was rated either as effective or partially effective in all 15 procedures $(100 \%)$ in the postmarketing surveillance 


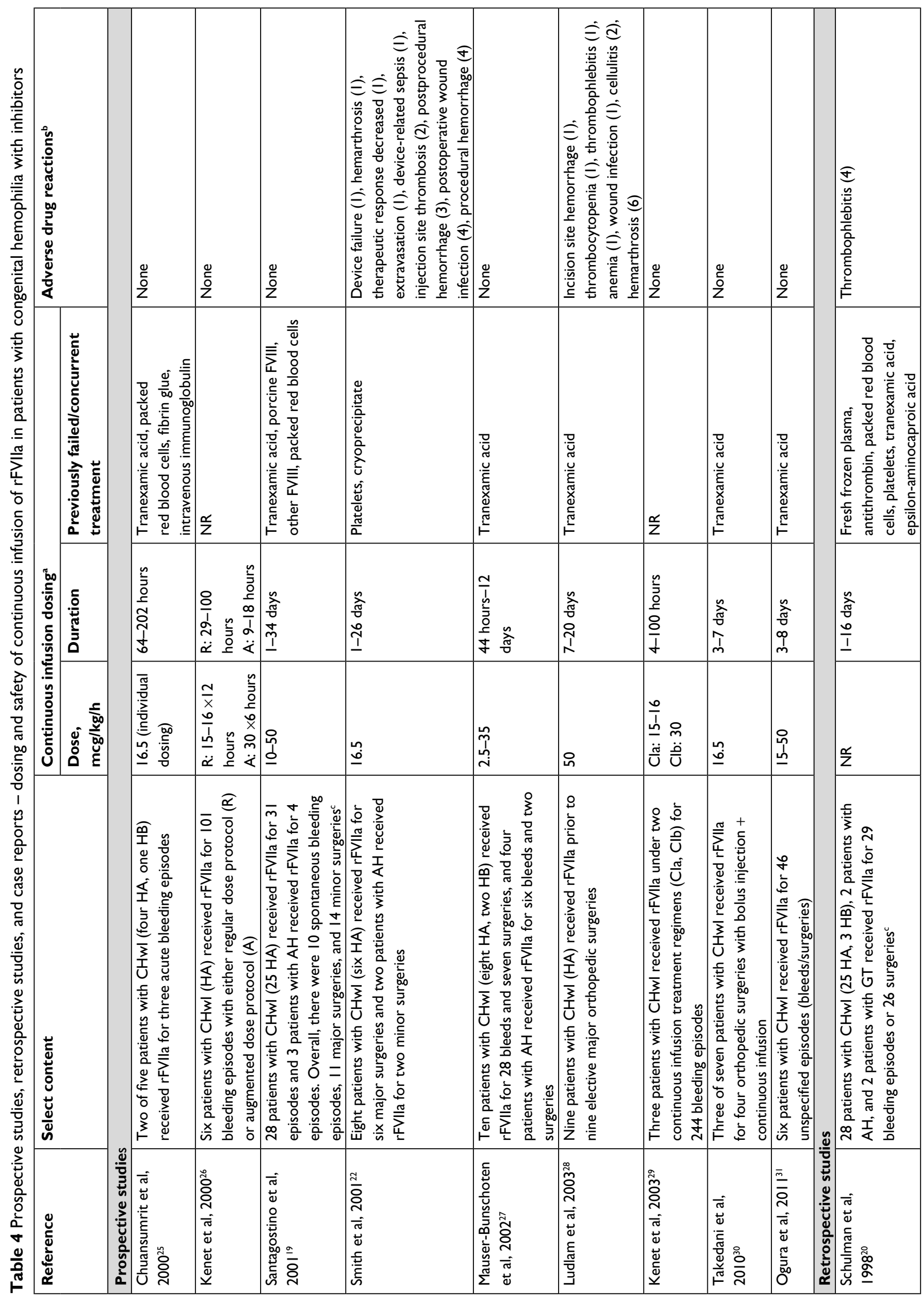




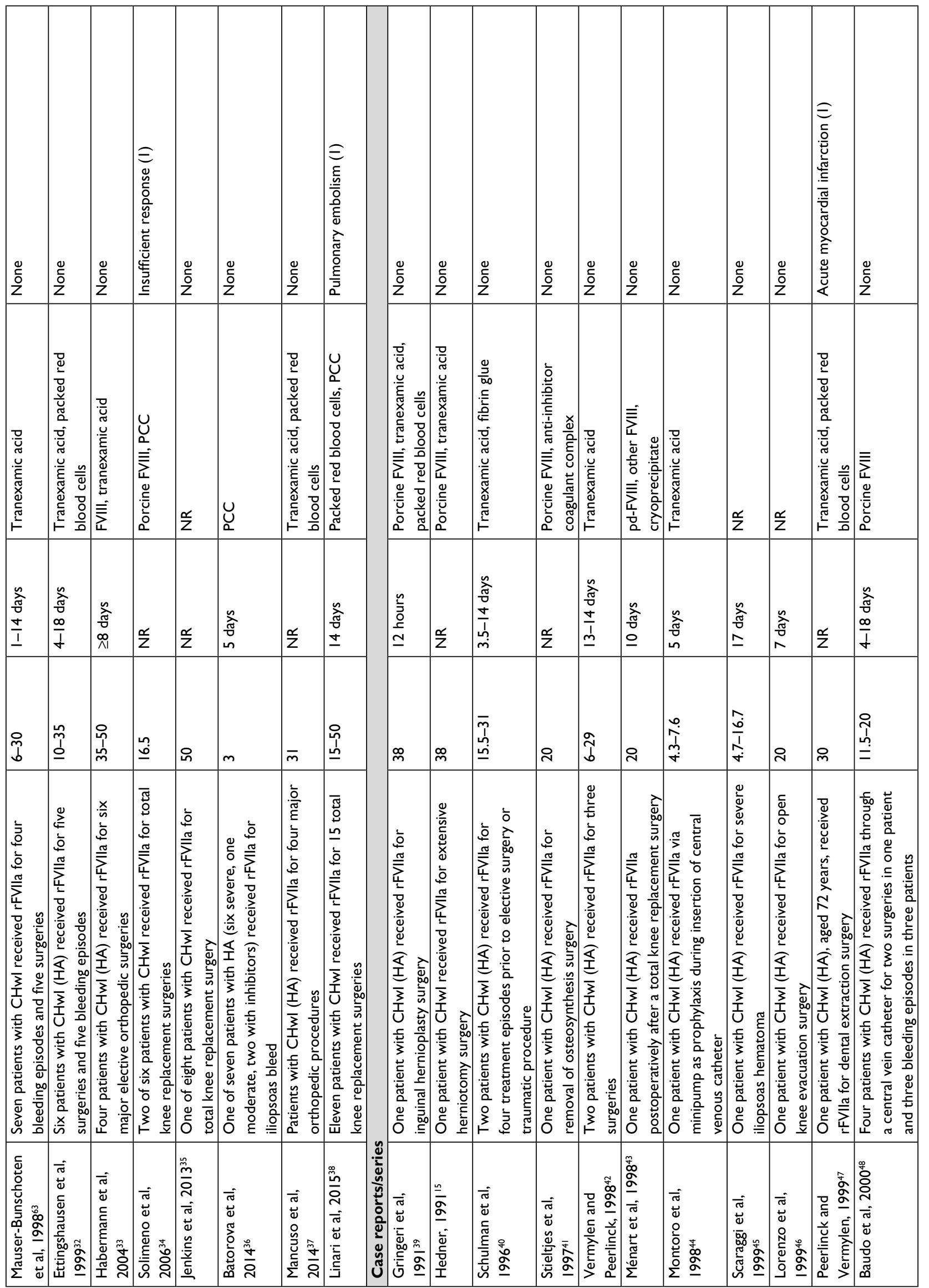




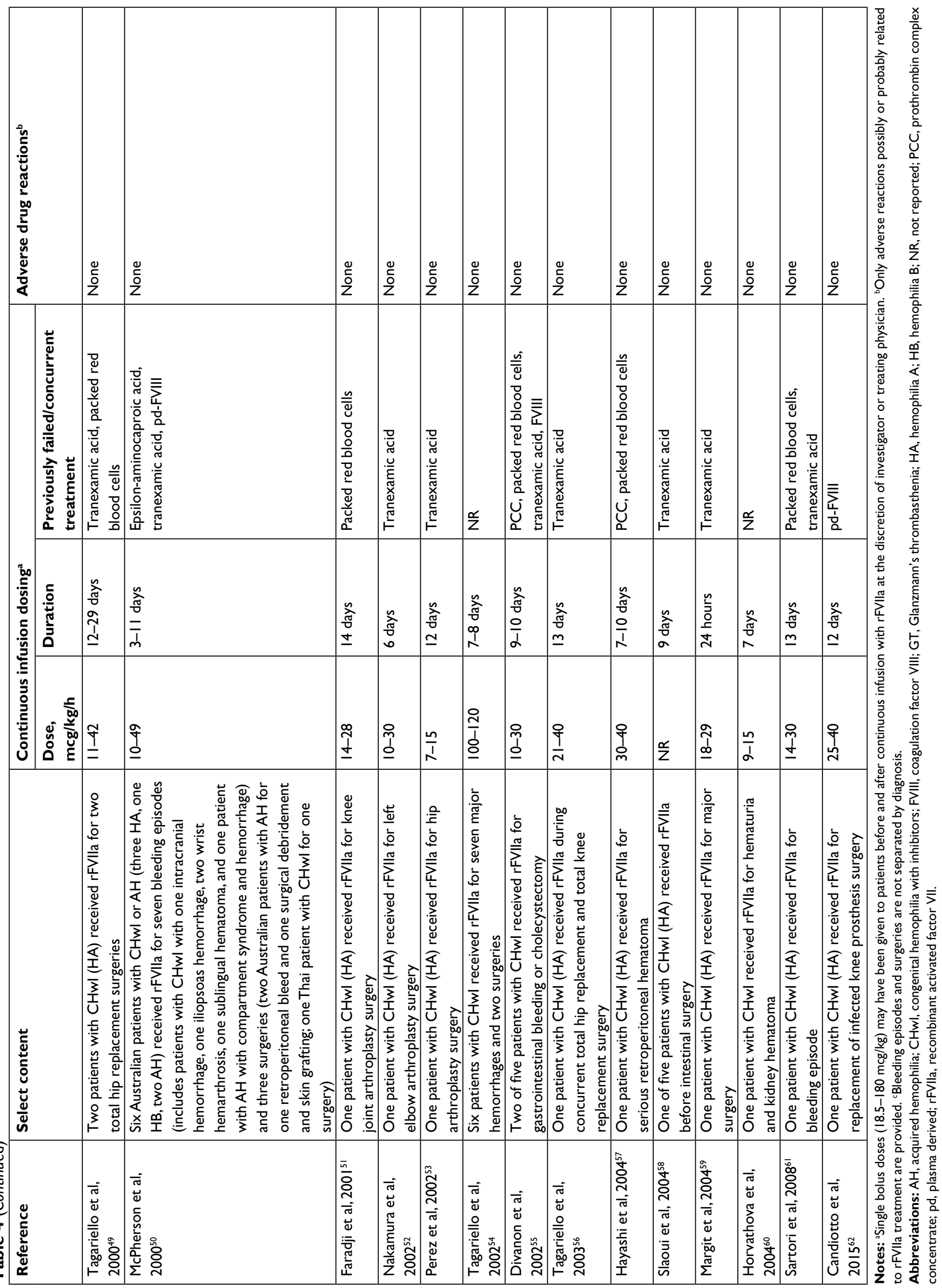


Table 5 Prospective studies, retrospective studies, and case reports - dosing and safety of continuous infusion of rFVIla in patients with congenital factor VII deficiency

\begin{tabular}{|c|c|c|c|c|c|}
\hline \multirow[t]{2}{*}{ Reference } & \multirow[t]{2}{*}{ Select content } & \multicolumn{3}{|c|}{ Continuous infusion dosing ${ }^{\mathrm{a}}$} & \multirow{2}{*}{$\begin{array}{l}\text { Adverse drug } \\
\text { reactions }^{\text {b }}\end{array}$} \\
\hline & & Dose, mcg/kg/h & Duration & $\begin{array}{l}\text { Previously failed/ } \\
\text { concurrent } \\
\text { treatment }\end{array}$ & \\
\hline \multicolumn{6}{|l|}{ Prospective studies } \\
\hline Tran et al, 20I I ${ }^{64}$ & $\begin{array}{l}\text { Ten patients with severe C7D received } \\
\text { rFVIla for } 13 \text { major and } 12 \text { minor surgeries }\end{array}$ & $0.4 I-4$ & $4-10$ days & $\begin{array}{l}\text { PCC, tranexamic } \\
\text { acid }\end{array}$ & $\begin{array}{l}\text { Major } \\
\text { perioperative } \\
\text { bleeding }(\mathrm{I}) \text {, } \\
\text { transient rFVIla } \\
\text { inhibitors (I) }\end{array}$ \\
\hline Mariani et al, 20I $\mathrm{I}^{65}$ & $\begin{array}{l}3 \text { of } 34 \text { patients with C7D received } \mathrm{rFVIla} \\
\text { for two major surgeries and one minor } \\
\text { surgery }\end{array}$ & $0.2-3.2$ & NR & NR & None \\
\hline \multicolumn{6}{|c|}{ Retrospective studies } \\
\hline $\begin{array}{l}\text { Schulman et al, } \\
2005^{66}\end{array}$ & $\begin{array}{l}\text { Seven patients with C7D received } \mathrm{rFVIIla} \mathrm{for} \\
12 \text { elective surgeries }\end{array}$ & $0.325-6.25$ & $2-7$ days & Tranexamic acid & None \\
\hline \multicolumn{6}{|l|}{ Case reports/series } \\
\hline $\begin{array}{l}\text { Jiménez-Yuste et al, } \\
2000^{67}\end{array}$ & $\begin{array}{l}\text { One pregnant patient with moderate C7D } \\
\text { received rFVlla during cesarean section } \\
\text { delivery }\end{array}$ & $1.66-3.33$ & 4 days & NR & None \\
\hline Katori et al, $2008^{68}$ & $\begin{array}{l}\text { Two pediatric patients with C7D } \\
\text { received rFVIla for cardiac surgery after } \\
\text { cardiopulmonary bypass termination }\end{array}$ & 30 & 8 hours & NR & None \\
\hline Nagao et al, 20I $4^{69}$ & $\begin{array}{l}\text { One patient with severe C7D received } \\
\text { rFVlla for left total hip replacement surgery }\end{array}$ & $\mathrm{I}-2$ & 7 days & NR & None \\
\hline $\begin{array}{l}\text { Rajpurkar et al, } \\
2014^{70}\end{array}$ & $\begin{array}{l}\text { One patient with severe C7D received } \\
\text { rFVIla for intracranial surgery }\end{array}$ & $4.5-9$ & 9 days & None & None \\
\hline Miyata et al, $2016^{71}$ & $\begin{array}{l}\text { One patient with asymptomatic C7D } \\
\text { received } r F V I l a \text { for a right middle and lower } \\
\text { lobectomy }\end{array}$ & $2.5-3.75$ & 3 days & None & None \\
\hline
\end{tabular}

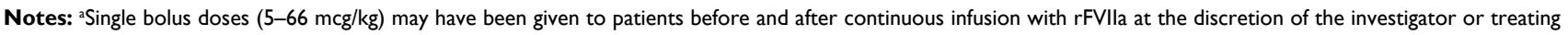
physician. 'Only adverse reactions possibly or probably related to $\mathrm{rFVlla}$ treatment are provided.

Abbreviations: C7D, congenital factor VII deficiency; NR, not reported; PCC, prothrombin complex concentrate; rFVIla, recombinant activated factor VII.

Table 6 Summary of continuous infusion-treated events in patients with congenital hemophilia with inhibitors and congenital factor VII deficiency

\begin{tabular}{|c|c|c|c|c|c|c|}
\hline & \multicolumn{2}{|c|}{ Congenital hemophilia with inhibitors } & \multicolumn{2}{|c|}{$\begin{array}{l}\text { Congenital factor VII } \\
\text { deficiency }\end{array}$} & \multicolumn{2}{|l|}{ Total } \\
\hline & No. of patients & $\begin{array}{l}\text { No. of episodes or } \\
\text { procedures }\end{array}$ & $\begin{array}{l}\text { No. of } \\
\text { patients }\end{array}$ & $\begin{array}{l}\text { No. of } \\
\text { episodes or } \\
\text { procedures }\end{array}$ & $\begin{array}{l}\text { No. of } \\
\text { patients }\end{array}$ & $\begin{array}{l}\text { No. of episodes or } \\
\text { procedures }\end{array}$ \\
\hline Clinical trial & 12 & 12 surgeries & NR & NR & 12 & 12 surgeries \\
\hline $\begin{array}{l}\text { Post-approval } \\
\text { study }\end{array}$ & 10 & 15 surgeries & NR & NR & 10 & 15 surgeries \\
\hline $\begin{array}{l}\text { Prospective } \\
\text { reports }\end{array}$ & 84 (includes $9 \mathrm{AH}$ ) & \begin{tabular}{|l|}
392 bleeds \\
55 surgeries \\
46 other (bleeds/surgeries)
\end{tabular} & 13 & 28 surgeries & 97 & $\begin{array}{l}392 \text { bleeds } \\
83 \text { surgeries } \\
46 \text { other (bleeds/surgery) }\end{array}$ \\
\hline $\begin{array}{l}\text { Retrospective } \\
\text { reports }\end{array}$ & $\begin{array}{l}64 \\
\text { (includes } 2 \mathrm{AH}, 2 \mathrm{GT} \text { ) }\end{array}$ & \begin{tabular}{|l}
39 bleeds \\
64 surgeries
\end{tabular} & 7 & 12 surgeries & 71 & $\begin{array}{l}39 \text { bleeds } \\
76 \text { surgeries }\end{array}$ \\
\hline $\begin{array}{l}\text { Case reports } \\
\text { and series }\end{array}$ & 45 & \begin{tabular}{|l|}
22 bleeds \\
31 surgeries \\
\end{tabular} & 6 & 6 surgeries & 51 & $\begin{array}{l}22 \text { bleeds } \\
37 \text { surgeries }\end{array}$ \\
\hline Total & $\begin{array}{l}215 \text { (includes II AH, } \\
2 \mathrm{GT} \text { ) }\end{array}$ & $\begin{array}{l}453 \text { bleeds } \\
\text { I } 77 \text { surgeries } \\
46 \text { other (bleeds/surgery) }\end{array}$ & 26 & 46 surgeries & 241 & $\begin{array}{l}453 \text { bleeds } \\
223 \text { surgeries } \\
46 \text { other (bleeds/surgery) }\end{array}$ \\
\hline
\end{tabular}

Abbreviations: AH, acquired hemophilia; GT, Glanzmann's thrombasthenia; NR, not reported. 
study. This generally high rate of efficacy is comparable to that observed with BIs in the only randomized parallel trial directly comparing these routes of administration ${ }^{23}$ and is also consistent with that previously reported for rFVIIa $\mathrm{BI}$ in registration trials (ie, 71\%-93\%), ${ }^{73-76}$ suggesting that no reduction in hemostatic efficacy occurs when rFVIIa is administered via CI vs BI.

Safety information was also extracted from all available CHwI reports. The most common SAEs previously reported with BI of rFVIIa in patients with CHwI in clinical trials and patient registries included thrombosis and decreased therapeutic response. ${ }^{16,18,77}$ Accumulated data from clinical trials and postmarketing studies found $13 \%$ of AEs in patients with $\mathrm{CHwI}$ to be thrombotic events, the majority of which $(60.3 \%)$ recovered without sequelae. ${ }^{78}$ Of the total 215 patients with $\mathrm{CHwI}$ identified in the current analysis who experienced 676 bleeding episodes or surgical procedures, 43 ADRs possibly or probably related to administration of rFVIIa were reported. These included four ADRs reported in the pivotal trial (all decreased therapeutic response, with equal numbers occurring in each treatment arm) and one local thrombophlebitis reported in the postmarketing surveillance study. This safety profile of rFVIIa CI for perioperative management is, therefore, largely consistent with and supported by previous reports of rFVIIa BI use in patients with CHwI, and suggests the absence of any new safety signals associated with the CI route of administration.

\section{Congenital factor VII deficiency}

Compared with CHwI, fewer records of rFVIIa CI in patients with C7D were identified, with reports including eight prospective studies, retrospective studies, and case reports/series, together presenting data from 26 patients who underwent 46 surgical procedures. Reported dosing in these studies was in the range of $0.2-30.0 \mathrm{mcg} / \mathrm{kg} / \mathrm{h}$, which was lower than that observed for patients with $\mathrm{CHwI}$, but consistent with a rate derived from dividing the recommended bolus dosing of $15-30 \mathrm{mcg} / \mathrm{kg}$ by the recommended 4-6-hour dosing interval. ${ }^{16}$ Lower rFVIIa dosing recommendations for factor replacement in C7D compared with use as a bypassing agent in CHwI are indicated in the current US prescribing information, with effective treatment for C7D reported with bolus dosing as low as $10 \mathrm{mcg} / \mathrm{kg}$. Of note, the difference in mechanism of action of rFVIIa in these two disease states may account for differences in bolus dosing requirements, as supraphysiological FVIIa levels may be necessary to initiate bypassing activity in patients with $\mathrm{CHwI}$ and to achieve comparable efficacy to that seen in patients with C7D. ${ }^{79}$ The safety profile of rFVIIa CI in patients with C7D was generally consistent with that observed in patients with $\mathrm{CHwI}$; of the 26 total patients identified with C7D, two ADRs in one patient possibly or probably related to rFVIIa administration were reported. While inhibitors to FVII replacement have been reported in patients with $\mathrm{C} 7 \mathrm{D}$ receiving plasma and recombinant replacement, only one patient was noted to have transient inhibitory activity resulting in temporary dose adjustment in a case series of CI. ${ }^{64}$

\section{Other considerations}

While not specifically evaluated or reported consistently in the literature, any use of rFVIIa by bolus or CI in the hospital setting needs to consider the severity or extensiveness of the bleed or surgical procedure and the need for coverage of postoperative physical therapy or rehabilitation. According to the prescribing information and based upon clinical studies, dosing was based upon weight and not upon age or body mass index. Although the limited amount of data comparing outcomes associated with CI vs bolus infusion limits our ability to recommend a CI dosing regimen, data from the pivotal open-label study in patients with $\mathrm{CHwI}$ support the effectiveness of a regimen including a $90 \mathrm{mcg} / \mathrm{kg}$ BI followed by $50 \mathrm{mcg} / \mathrm{kg} / \mathrm{h} \mathrm{CI} .{ }^{23}$ Furthermore, an optimal dosing regimen in the context of C7D would likely include bolus dosing to achieve the desired FVIIa level for a particular procedure (eg, $15-30 \mathrm{mcg} / \mathrm{kg}$ as recommended in the prescribing information) followed by CI to maintain this level. Overall, the lack of any new safety signals associated with intensive rFVIIa treatment via CI, especially severe thrombotic events, is a key finding of our analysis and may be important in informing the potential use of this type of treatment.

Use of antifibrinolytics with rFVIIa has been described in many previous studies, although specific impact on the efficacy of rFVIIa has not been systematically studied. Antifibrinolytic use has not been reported to have an impact on the risk of thrombotic events. As noted in Tables 4 and 5 , this is a common concurrent medication used for surgery in patients with $\mathrm{CHwI}$ and $\mathrm{C} 7 \mathrm{D}$, and not clearly associated with a difference in thrombotic risk in this review. Superficial thrombophlebitis in a peripheral vein used for CI is noted in this review in several cases, including the case series in which antifibrinolytics have been used, and the use of undiluted rFVIIa was noted as being a causative factor, not antifibrinolytics. One report does describe a 72-year-old hypertensive smoker who developed an acute myocardial event following a dental surgery where tranexamic acid $1,000 \mathrm{mg}$ intravenous was administered preoperatively. ${ }^{47}$ 
The recent development of new non-factor therapeutics for patients with CHwI (eg, emicizumab, fitusiran, concizumab) also raises new challenges in prescribing concomitant rFVIIa, and therefore, careful evaluation and monitoring of the safety and effectiveness of rFVIIa in this context should be performed.

\section{Limitations}

A key limitation to this analysis is the inconsistent use of concomitant hemostatic agents and highly variable dosing of rFVIIa for BIs and CI across patients and reports, which complicates the interpretation of safety and efficacy assessments. Therefore, even though hemostatic management was achieved in many cases, efficacy may or may not be due solely to CI of rFVIIa, and direct comparisons cannot be made between studies. Additionally, inconsistent definitions of efficacy were used across reports, complicating the ability to draw conclusions across studies. However, these limitations are common in the context of rare diseases, which rely on real-world data, and our analysis benefited from systematically searching the published literature to obtain the maximum amount of patient data relevant to rFVIIa CI in populations of interest. We also cannot exclude the possibility that some reports may have included partially overlapping patient populations, and therefore, some individuals may have been included in our analysis more than once.

A key opportunity for future investigation may include performing a direct comparison between $\mathrm{BI}$ and $\mathrm{CI}$ of rFVIIa in patients with $C 7 D$, the absence of which complicates the ability to recommend therapeutic dose guidelines for CI administration in this patient population. This review also identified a combination of monitoring strategies including FVII activity to maintain a minimum target activity particularly in C7D and use of thrombelastography; although from this type of review, it is similarly difficult to identify the value in the monitoring strategies or specific target FVII:C ranges, and thrombelastography parameters were best described in the case of intracranial surgery. ${ }^{70}$

\section{Conclusion}

This review involved a systematic search of the published literature to identify reports of rFVIIa CI for hemostatic management in patients with CHwI or C7D, and it summarizes all available safety, efficacy, and dosing information. Efficacy of rFVIIa CI appeared to be high and comparable to that of BI, with reported ADRs consistent with the established safety profile of rFVIIa BI. CI may be a useful alternative to BIs for the perioperative management of bleeding in some patients with CHwI or C7D.

\section{Acknowledgments}

Writing assistance was provided by Anna Abt, $\mathrm{PhD}$, and Nicole Yohn, PhD, of ETHOS Health Communications, Yardley, Pennsylvania, with financial assistance from Novo Nordisk Inc., in compliance with international guidelines on Good Publication Practice.

\section{Disclosure}

M Rajpurkar has received honoraria from Novo Nordisk Inc. DL Cooper is an employee of Novo Nordisk Inc. The authors report no other conflicts of interest in this work.

\section{References}

1. Batorova A, Martinowitz U. Continuous infusion of coagulation factors Haemophilia. 2002;8(3):170-177.

2. Martinowitz UP, Schulman S. Continuous infusion of factor concentrates: review of use in hemophilia $\mathrm{A}$ and demonstration of safety and efficacy in hemophilia B. Acta Haematol. 1995;94(suppl 1):35-42.

3. Brinkhous KM. Hemophilia. Bull NY Acad Med. 1954;30(5):325-342.

4. Bona RD, Weinstein RA, Weisman SJ, Bartolomeo A, Rickles FR. The use of continuous infusion of factor concentrates in the treatment of hemophilia. Am J Hematol. 1989;32(1):8-13.

5. Hathaway WE, Christian MJ, Clarke SL, Hasiba U. Comparison of continuous and intermittent factor VIII concentrate therapy in hemophilia A. Am J Hematol. 1984;17(1):85-88.

6. Mcmillan CW, Webster WP, Roberts HR, Blythe WB. Continuous intravenous infusion of factor VIII in classic haemophilia. Br J Haematol. 1970;18(6):659-667.

7. Schulman S, Varon D, Keller N, Gitel S, Martinowitz U. Monoclonal purified F VIII for continuous infusion: stability, microbiological safety and clinical experience. Thromb Haemost. 1994;72(3):403-407.

8. Weinstein RE, Bona RD, Rickles FR. Continuous infusion of monoclonal antibody-purified factor VIII. Am J Hematol. 1991;36(3):211-212.

9. Varon D, Martinowitz U. Continuous infusion therapy in haemophilia. Haemophilia. 1998;4(4):431-435.

10. Srivastava A, Brewer AK, Mauser-Bunschoten EP, et al. Guidelines for the management of hemophilia. Haemophilia. 2013;19(1):e1-e47.

11. Batorova A, Martinowitz U. Intermittent injections vs. continuous infusion of factor VIII in haemophilia patients undergoing major surgery. Br J Haematol. 2000;110(3):715-720.

12. Bidlingmaier C, Deml MM, Kurnik K. Continuous infusion of factor concentrates in children with haemophilia A in comparison with bolus injections. Haemophilia. 2006;12(3):212-217.

13. Martinowitz U, Luboshitz J, Bashari D, et al. Stability, efficacy, and safety of continuously infused sucrose-formulated recombinant factor VIII (rFVIII-FS) during surgery in patients with severe haemophilia. Haemophilia. 2009;15(3):676-685.

14. Jurlander B, Thim L, Klausen NK, et al. Recombinant activated factor VII (rFVIIa): characterization, manufacturing, and clinical development. Semin Thromb Hemost. 2001;27(4):373-384.

15. Hedner U. Experiences with recombinant factor VIIa in haemophiliacs. Curr Stud Hematol Blood Transfus. 1991;(58):63-68.

16. NovoSeven RT [package insert]. Plainsboro, NJ; Novo Nordisk Inc.; 2017.

17. Schulman S. Safety, efficacy and lessons from continuous infusion with rFVIIa. rFVIIa-CI Group. Haemophilia. 1998;4(4):564-567.

18. Shapiro AD, Gilchrist GS, Hoots WK, Cooper HA, Gastineau DA. Prospective, randomised trial of two doses of rFVIIa (NovoSeven) in haemophilia patients with inhibitors undergoing surgery. Thromb Haemost. 1998;80(5):773-778.

19. Santagostino E, Morfini M, Rocino A, Baudo F, Scaraggi FA, Gringeri A. Relationship between factor VII activity and clinical efficacy of recombinant factor VIIa given by continuous infusion to patients with factor VIII inhibitors. Thromb Haemost. 2001;86(4):954-958. 
20. Schulman S, D'Oiron R, Martinowitz U, et al. Experiences with continuous infusion of recombinant activated factor VII. Blood Coagul Fibrinolysis. 1998;9(supp1 1):S97-S101.

21. Schulman S; rFVIIa-CI Group. Continuous infusion of recombinant factor VIIa in hemophilic patients with inhibitors: safety, monitoring, and cost effectiveness. Semin Thromb Hemost. 2000;26(4):421-424.

22. Smith MP, Ludlam CA, Collins PW, et al. Elective surgery on factor VIII inhibitor patients using continuous infusion of recombinant activated factor VII: plasma factor VII activity of $10 \mathrm{IU} / \mathrm{ml}$ is associated with an increased incidence of bleeding. Thromb Haemost. 2001;86(4):949-953.

23. Pruthi RK, Mathew P, Valentino LA, et al. Haemostatic efficacy and safety of bolus and continuous infusion of recombinant factor VIIa are comparable in haemophilia patients with inhibitors undergoing major surgery. Results from an open-label, randomized, multicenter trial. Thromb Haemost. 2007;98(4):726-732.

24. Takedani H, Shima M, Horikoshi Y, et al. Ten-year experience of recombinant activated factor VII use in surgical patients with congenital haemophilia with inhibitors or acquired haemophilia in Japan. Haemophilia. 2015;21(3):374-379.

25. Chuansumrit $\mathrm{A}$, Isarangkura $\mathrm{P}$, Angchaisuksiri $\mathrm{P}$, et al. Controlling acute bleeding episodes with recombinant factor VIIa in haemophiliacs with inhibitor: continuous infusion and bolus injection. Haemophilia. 2000;6(2):61-65.

26. Kenet G, Lubetsky A, Gitel S, Luboshitz J, Varon D, Martinowitz U. Treatment of bleeding episodes in patients with hemophilia and an inhibitor: comparison of two treatment protocols with recombinant activated factor VII. Blood Coagul Fibrinolysis. 2000;11(suppl 1):S35-S38.

27. Mauser-Bunschoten EP, Koopman MM, Goede-Bolder AD, et al. Efficacy of recombinant factor VIIa administered by continuous infusion to haemophilia patients with inhibitors. Haemophilia. 2002;8(5):649-656.

28. Ludlam CA, Smith MP, Morfini M, Gringeri A, Santagostino E, Savidge GF. A prospective study of recombinant activated factor VII administered by continuous infusion to inhibitor patients undergoing elective major orthopaedic surgery: a pharmacokinetic and efficacy evaluation. Br J Haematol. 2003;120(5):808-813.

29. Kenet G, Lubetsky A, Luboshitz J, Martinowitz U. A new approach to treatment of bleeding episodes in young hemophilia patients: a single bolus megadose of recombinant activated factor VII (NovoSeven). $J$ Thromb Haemost. 2003;1(3):450-455.

30. Takedani H, Kawahara H, Kajiwara M. Major orthopaedic surgeries for haemophilia with inhibitors using rFVIIa. Haemophilia. 2010;16(2):290-295.

31. Ogura T, Horikoshi Y, Kakazu M, et al. Recombinant factor VII (rFVIIa) by continuous infusion for pediatric haemophilia patients with inhibitors. J Thromb Haemost. 2011;9(suppl 2):968.

32. Ettingshausen CE, Auerswald G, Auberger K, Saguer IM, Kreuz W. Efficacy and safety of continuous infusion of recombinant factor VIIa in pediatric hemophilia A patients with high titer inhibitors. Blood. 1999;94:1052.

33. Habermann B, Hochmuth K, Hovy L, Scharrer I, Kurth AH. Management of haemophilic patients with inhibitors in major orthopaedic surgery by immunadsorption, substitution of factor VIII and recombinant factor VIIa (NovoSeven): a single centre experience. Haemophilia. 2004;10(6):705-712.

34. Solimeno LP, Perfetto OS, Pasta G, Santagostino E. Total joint replacement in patients with inhibitors. Haemophilia. 2006;12(suppl 3):113-116.

35. Jenkins PJ, Ekrol I, Lawson GM. Total knee replacement in patients with haemophilia: the Scottish experience. Scott Med J. 2013;58(4):223-227.

36. Batorova A, Prigancova T, Jankovicova D. Management of iliopsoas hematomas in patients with hemophilia. Poster presented at: 7th Annual Congress of the European Association for Haemophilia and Allied Disorders; 2014; Brussels, Belgium.

37. Mancuso ME, Pasta G, Fasulo MR, Peyvandi F, Solimeno LP, Santagostino E. Elective orthopedic surgery in patients with hemophilia and inhibitors: still a big challenge for haematologists? Poster P-T-051 presented at: 31 st International Congress of the World Federation of Hemophilia; 2014; Melbourne, Australia.
38. Linari S, Carulli C, Martini C, et al. Short and long-term outcomes in hemophilia patients with inhibitors undergoing orthopedic prosthetic surgery. Poster C046 presented at: 45th National Congress of the Italian Society of Hematology; 2015; Florence, Italy.

39. Gringeri A, Santagostino E, Mannucci PM. Failure of recombinant activated factor VII during surgery in a hemophiliac with high-titer factor VIII antibody. Haemostasis. 1991;21(1):1-4.

40. Schulman S, Bech Jensen M, Varon D, et al. Feasibility of using recombinant factor VIIa in continuous infusion. Thromb Haemost. 1996;75(3):432-436.

41. Stieltjes N, Ounnoughene N, Vassilieff D, Sultan Y. Failure of recombinant factor VIIa to control surgical bleeding in a severe hemophilia A patient with inhibitor and possible DIC. Poster PS-202 presented at: 15 th Congress of the International Society on Thrombosis and Haemostasis; 1997; Florence, Italy.

42. Vermylen J, Peerlinck K. Optimal care of inhibitor patients during surgery. Eur J Haematol Suppl. 1998;63:15-17.

43. Ménart C, Cognet V, Petit PY, Massignon D, Négrier C. Management of an anti-factor VIII inhibitor occurring during surgical procedure with continuous infusion of Novoseven. Blood Coagul Fibrinolysis. 1998;9(3):289-290.

44. Montoro JB, Altisent C, Pico M, Cabañas MJ, Vila M, Puig LL. Recombinant factor VIIa in continuous infusion during central line insertion in a child with factor VIII high-titre inhibitor. Haemophilia. 1998;4(5):762-765.

45. Scaraggi FA, de Mitrio V, Marino R, et al. Treatment with recombinant activated factor VII in a patient with hemophilia A and an inhibitor: advantages of administration by continuous infusion over bolus intermittent injections. Blood Coagul Fibrinolysis. 1999;10(1):33-38.

46. Lorenzo JI, Montoro JM, Aznar JA. Postoperative use of rFVIIa by continuous infusion in a haemophilic boy. Haemophilia. 1999;5(2): 135-138.

47. Peerlinck K, Vermylen J. Acute myocardial infarction following administration of recombinant activated factor VII (Novo Seven) in a patient with haemophilia A and inhibitor. Thromb Haemost. 1999;82(6):1775-1776.

48. Baudo F, Redaelli R, Caimi TM, Mostarda G, Somaini G, de Cataldo F. The continuous infusion of recombinant activated factor VIIa (rFVIIa) in patients with factor VIII inhibitors activates the coagulation and fibrinolytic systems without clinical complications. Thromb Res. 2000;99(1):21-24.

49. Tagariello G, de Biasi E, Gajo GB, et al. Recombinant FVIIa (NovoSeven) continuous infusion and total hip replacement in patients with haemophilia and high titre of inhibitors to FVIII: experience of two cases. Haemophilia. 2000;6(5):581-583.

50. McPherson J, Sutcharitchan P, Lloyd J, Street A, Nelleman Jorgensen L, Yang SI. Experience with continuous infusion of recombinant activated factor VII in the Asia-Pacific region. Blood Coagul Fibrinolysis. 2000;11 (suppl 1):S31-S34.

51. Faradji A, Bonnomet F, Lecocq J, et al. Knee joint arthroplasty in a patient with haemophilia $\mathrm{A}$ and high inhibitor titre using recombinant factor VIIa (NovoSeven): a new case report and review of the literature. Haemophilia. 2001;7(3):321-326.

52. Nakamura M, Terashima K, Takashima Y, Amano K, Horikoshi Y, Mimaya J. [Continuous infusion of recombinant activated factor VII during and after elbow arthroplasty in a hemophilia A patient with inhibitors]. Rinsho Ketsueki. 2002;43(3):183-188.

53. Perez R, Martinez RL, Piñero A, Sosa R. Sequential treatment with bolus and continuous infusion of recombinant factor VIIa for hip arthroplasty in a patient with haemophilia A and inhibitor. Haemophilia. 2002;8(6):822-825.

54. Tagariello G, Radossi P, de Biasi E, Ri Sato R, Davoli PG. Flexibility of recombinant FVIIa continuous infusion in patients with haemophilia and inhibitors. Poster PO39 presented at: 25th International Congress of the World Federation of Hemophilia; 2002; Seville, Spain.

55. Divanon F, Hecquard C, Borel-Derlon A. Experience with use of recombinant activated factor VII. J Clin Pharm Ther. 2002;27(2):133-138. 
56. Tagariello G, Bisson R, Radossi P, et al. Concurrent total hip and knee replacements in a patient with haemophilia with inhibitors using recombinant factor VIIa by continuous infusion. Haemophilia. 2003;9(6): 738-740.

57. Hayashi T, Tanaka I, Shima M, et al. Unresponsiveness to factor VIII inhibitor bypassing agents during haemostatic treatment for lifethreatening massive bleeding in a patient with haemophilia A and a high responding inhibitor. Haemophilia. 2004;10(4):397-400.

58. Slaoui M, Lambert T, Stieltjes N, Claeyssens S, Borel-Derlon A; Study Group. Intestinal surgery with activated recombinant factor VII prophylaxis in patients with haemophilia A and high responding inhibitors: a report of five cases. Blood Coagul Fibrinolysis. 2004;15(8):687-691.

59. Margit S, Pavel T, Smaranda A, et al. Successful major surgery with minimal dosage of rFVIIa in a hemophiliac with high level of alloantibodies to factor VIII. Poster PO54 presented at: 26th International Congress of the World Federation of Hemophilia; 2004; Bangkok, Thailand.

60. Horvathova D, Batorova A, Hurtova Z, Mistrik M. Successful treatment of hematuria and kidney hematoma with continuous infusion of rFVIIa in hemophilia patient with inhibitor. Poster PO28 presented at: 26th International Congress of the World Federation of Hemophilia; 2004; Bangkok, Thailand.

61. Sartori R, Bisson R, Baars GW, et al. One-stage replacement of infected knee prosthesis in a patient with haemophilia A and high titre of inhibitors. Haemophilia. 2008;14(2):375-377.

62. Candiotto L, Fullone FW, Ricciardi A, Radossi P, Tagariello G. Correction of knee flexion contracture at the time of surgical fixation of a femoral supracondylar fracture in a haemophiliac with inhibitors. Blood Transfus. 2015;13(2):333-335.

63. Mauser-Bunschoten EP, de Goede-Bolder A, Wielenga JJ, Levi M, Peerlinck K. Continuous infusion of recombinant factor VIIa in patients with haemophilia and inhibitors. Experience in The Netherlands and Belgium. Neth J Med. 1998;53(6):249-255.

64. Tran HT, Tjønnfjord GE, Paus A, Holme PA. rFVIIa administered by continuous infusion during surgery in patients with severe congenital FVII deficiency. Haemophilia. 2011;17(5):764-770.

65. Mariani G, Dolce A, Batorova A, et al. Recombinant, activated factor VII for surgery in factor VII deficiency: a prospective evaluation - the surgical STER. Br J Haematol. 2011;152(3):340-346.

66. Schulman S, Tjønnfjord GE, Wallensten R, Martinowitz U, Kenet G. Continuous infusion of recombinant factor VIIa for surgery in patients with deficiency of factor VII. Thromb Haemost. 2005;94(6):1177-1180.

67. Jiménez-Yuste V, Villar A, Morado M, et al. Continuous infusion of recombinant activated factor VII during caesarean section delivery in a patient with congenital factor VII deficiency. Haemophilia. 2000;6(5):588-590.
68. Katori N, Yamada T, Takeda J. Pharmacokinetics of recombinant activated factor VII (rFVIIa) in patients with factor VII deficiency. Poster A1282 presented at: 59th Annual Meeting of the American Society of Anesthesiologists; 2008; Orlando, FL.

69. Nagao A, Hanabusa H, Takedani H. Continuous infusion of rFVIIa during surgery in a FVII-deficient patient: a case report from Japan. Haemophilia. 2014;20(1):e110-e112.

70. Rajpurkar M, Callaghan M, Frey MJ, Set K, Chugani H, Sood S. Management of intracranial surgery for refractory epilepsy in severe factor VII deficiency: choosing the optimal dosing regimen. Haemophilia. 2014;20(3):e234-e237.

71. Miyata N, Isaka M, Kojima $\mathrm{H}$, et al. Continuous infusion of recombinant activated factor VII for bleeding control after lobectomy in a patient with inherited factor VII deficiency. Gen Thorac Cardiovasc Surg. 2016;64(3):177-180.

72. Christensen A, Jensen JT, Nøhr AM, Cooper DL. Room-temperaturestable recombinant activated coagulation factor VII recombinant: chemical and microbiologic stability over 24 hours during continuous in vitro infusion. Clin Ther. 2011;33(12):1997-2001.

73. Bech RM. Recombinant factor VIIa in joint and muscle bleeding episodes. Haemostasis. 1996;26(suppl 1):135-138.

74. Lusher J, Ingerslev J, Roberts H, Hedner U. Clinical experience with recombinant factor VIIa. Blood Coagul Fibrinolysis. 1998;9(2): $119-128$.

75. Lusher JM. Recombinant factor VIIa (NovoSeven) in the treatment of internal bleeding in patients with factor VIII and IX inhibitors. Haemostasis. 1996;26(suppl 1):124-130.

76. Lusher JM, Roberts HR, Davignon G, et al. A randomized, double-blind comparison of two dosage levels of recombinant factor VIIa in the treatment of joint, muscle and mucocutaneous haemorrhages in persons with haemophilia A and B, with and without inhibitors. rFVIIa Study Group. Haemophilia. 1998;4(6):790-798.

77. Parameswaran R, Shapiro AD, Gill JC, Kessler CM; HTRS Registry Investigators. Dose effect and efficacy of rFVIIa in the treatment of haemophilia patients with inhibitors: analysis from the Hemophilia and Thrombosis Research Society Registry. Haemophilia. 2005;11(2):100-106.

78. Neufeld EJ, Négrier C, Arkhammar P, et al. Safety update on the use of recombinant activated factor VII in approved indications. Blood Rev. 2015;29(suppl 1):S34-S41.

79. Monroe DM, Hoffman M, Oliver JA, Roberts HR. Platelet activity of high-dose factor VIIa is independent of tissue factor. Br J Haematol. 1997;99(3):542-547.
Journal of Blood Medicine

\section{Publish your work in this journal}

The Journal of Blood Medicine is an international, peer-reviewed, open access, online journal publishing laboratory, experimental and clinical aspects of all aspect pertaining to blood based medicine including but not limited to: Transfusion Medicine; Blood collection, Donor issues, Transmittable diseases, and Blood banking logistics; Immunohematology; Artificial and alternative

\section{Dovepress}

blood based therapeutics; Hematology; Biotechnology/nanotechnology of blood related medicine; Legal aspects of blood medicine; Historical perspectives. The manuscript management system is completely online and includes a very quick and fair peer-review system. Visit http://www.dovepress.com/ testimonials.php to read real quotes from published authors. 